\title{
Enabling Resilient Multi-Mode Controller in Power System With Re and Bes Using Firefly Algorithm
}

\author{
Herlambang Setiadi', N. Mithulananthan², and Rakibuzzaman Shah ${ }^{3}$, Awan Uji Krismanto ${ }^{4}$ \\ ${ }^{1}$ School of Advanced Technology and Multidiciplinary, Universitas Airlangga, Campus C UNAIR Mulyorejo, Surabaya, 60115, Indonesia \\ ${ }^{2}$ School of Information Technology and Electrical Engineering, The University of Queensland, St Lucia, QLD 4072, Australia \\ ${ }^{3}$ School of Engineering, Information Technology and Physical Sciences, Federation University Australia, Mt Helen, VIC 3353, Australia \\ ${ }^{4}$ Electrical Engineering Department, Institut Teknologi Nasional Malang, Malang, 65145, Indonesia \\ Corresponding author: Rakibuzzaman Shah $\underline{\text { m.shah@federation.edu.au }}$
}

\begin{abstract}
This paper proposed a damping method for enhancing oscillatory stability performance of power systems with high penetration of renewable energy by a resilient wide-area multi-mode controller. The resilient wide-area multi-mode controller is used as an additional controller in a renewable energy system with a battery energy storage to enhance the damping of the critically weak modes. The weak modes are likely to be triggered in the event of line outages or any other disturbances, and the system may become unstable in the absence of proper corrective and preventive control. A firefly algorithm has been employed to design such a controller. Eigenvalue analysis and time-domain simulation are used to analyze the performance of the proposed controller in a realistic representative power system. From the simulation results, it is evident that the oscillatory stability performance of the renewable rich power system can be enhanced with the proposed control to keep the damping on critical modes to the industrial standards. Furthermore, renewable energy penetration can be increased significantly in the realistic representative system by introducing the proposed controller without disturbing the oscillatory stability margin.
\end{abstract}

INDEX TERMS: BESS; damping; eigenvalue; firefly algorithm; oscillatory stability; renewable energy

\section{INTRODUCTION}

$\mathrm{P}$ ower electronic devices are widely used in renewable energy systems (RESs) such as wind, PV, and other emerging technologies. The number of power electronic devices will be significantly increased in future power grids due to the high penetration of RESs, battery energy storage system (BESS), and high voltage DC (HVDC) interconnectors. These power electronics devices may be widely used in the future at the load side as well to make electricity usage more efficient. However, power electronics and their controllers could bring new challenges in maintaining power system stability, especially small signal stability. Apart from this, other major challenge associated with renewable energy generation is the uncertainty in output power $[1,2]$. As reported in [3], the integration of large-scale PV plant could affect the oscillatory stability or small-signal stability due to the different dynamic characteristics and reverse power flow in the system. It is observed that the damping ratio of the electromechanical mode changed with the penetrations of large-scale PV. The impact of wind power plant penetration on oscillatory stability is reported in [4]. From this research, it is found that the penetration of wind power generation may bring both positive or negative influence on the oscillatory stability of power systems. It is also found in [4] that the integration of wind power may influence the other oscillation modes of the power systems. Research efforts in [5] have investigated the effect of the intermittent power output of power plants on the oscillatory stability of the system. Two different case studies are considered in that paper. The uncertainty of wind power system is modeled with stochastic operating condition. Eigenvalue analysis, damping performance analysis and participation analysis are used to investigate the impact of inttermittent power ouput of wind power system.

It is also noticeable that the uncertainty in the power output of wind could adversely affect the oscillatory stability of the system. The influence of uncertain power output of PV generation on oscillatory condition is reported in [6]. The PV generation is modelled such as two stage PV system. Two stage PV generation is consisting of boost converter and the associated controller as the MPPT of PV generation, DC link capacitor as buffer between boost converter and inverter. While inverter is used as a link between PV generation and grid. Two case studies are considered in the paper. The first case study considered the two area power system while in the second case study the IEEE 39-bus system is used. Both time domain simulation and damping performance assesment are used to investigate the impact of uncertain power output of PV generation. From the simulation results, it is evident that the uncertainty in output power of PV plant could have an adverse effect on oscillatory stability of power system. A number of research efforts have been made to use the BESS to overcome the adverse effects of renewable generations.

The research effort in [7] has investigated the impact of BESS on low-frequency oscillation for both local and global modes with the renewable energy power system. In [7], two-area four machine power system is used as the test system. Some modification 
has been made in the test system (e.g. replacing one synchronous generator in area 1 with wind and PV generation). It is evident from the results presented in the paper that by replacing one synchronous generator with renewable based generation could increased the oscillatory condition of electromechanical modes. Furthermore, BESS is also added in the area 1. It is found that the integration of BESS could enhance the dynamic performance of the system even though a synchronous generator is replaced with RESs. The research works presented in [8] were devoted to analyze the impact of BESS integration on modal interaction with high penetration of renewables. Several case studies are considered in this paper to see the impact of BESS controller on modal interation of power system. From the results, it is found that the control gain variation in the BESS system could significantly affect the modal interaction in the specific mode. Although the BESS could enhance the dynamic performance of the system with renewable energy, the influence of BESS on oscillatory stability may not be noteworthy. Hence it is essential to add additional controllers such as the power oscillation damping (POD) at BESS to enhance the damping performance of the critical modes.

The application of POD in power systems with renewable generations and BESS is reported in [9]. The analysis has been conducted in the two-area power system and the Java-Indonesia power grid (three-area power system). The POD is designed to be resilient to communication failures. From the simulation results, it is evident that the damping performance of the critical modes can be enhanced by adding PODs at the excitation system. It is also found that POD can be designed to be resilient to communication failures. However, the implication of the control failures on the overall dynamic performance of the system was ignored. Moreover, the implication of synchronous generation replacement with such control function was also overlooked in [9].

Hence, it is essential to design a controller that can tackle both communication and controller failures. Research in [10] has proposed a new control method called resilient wide-area multi-mode controller (MMC). The controller was added to the generator excitation system. From the simulation results, it is evident that the proposed controller can tackle both communication and controller failures. However, with the increasing penetration of renewable energy sources, these synchronous generators with auxiliary control would be replaced with renewable energy systems (RESs) in the future. Therefore, it is important to implement such controllers in the renewable energy system and BESS. Moreover, the multi-mode controller was proposed using the Bat algorithm [10]. From the result, it is evident that the computationally costly Bat algorithm based MMC could provide efficient control for inter-area mode. Therefore, it is necessary to choose another algorithm such as the firefly algorithm (FA) for designing MMC on renewable energy and BESS since FA has the advantages for dealing with highly non-linear problems with low computational cost. Hence, the aim of this paper is to design a low computational cost, simple, and reliable auxiliary controller of renewable energy generations and BESS using FA.

The rest of the paper is organized as follows: Section II provides the modelling overview of wind power system, PV system, and BESS. The industry standard of small signal stability and indices for measuring the robustness of the system performance are also illustrated in Section II. The controller design procedure is discussed in Section III. The results and discussions of this research are presented in Section IV. The conclusions and the contributions of the research are highlighted in Section V.

\section{Modelling Overview}

In this section, the modelling of wind energy conversion system, PV power plant, and battery energy storage system are briefly explained. Furthermore, the indices to measures the non-linear response and the robustness of the system are also explained in this section.

\section{A. Wind Power System}

The permanent magnet synchronous generator-based wind power plant is considered to represent the wind power system in this research. The wind energy conversion system (WECS) consists of the dynamic representation of permanent magnet synchronous generator, wind turbine, rotor, and grid side converter including the associated controllers. The dynamic model of WECS is represented by the mathematical equations for simulation studies. The mathematical representation of permanent magnet synchronous generator can be described using (1), (2), and (3) [11].

$$
\begin{gathered}
\frac{d i_{d}}{d t}=\frac{1}{L_{d s}+L_{i s}}\left(-R_{s} i_{d}+\omega_{e}\left(L_{q s}+L_{i s}\right) i_{q}+u_{d}\right) \\
\frac{d i_{q}}{d t}=\frac{1}{L_{q s}+L_{i s}}\left(-R_{s} i_{q}+\omega_{e}\left[\left(L_{d s}+L_{i s}\right) i_{q}+\psi_{f}\right]+u_{d}\right) \\
\omega_{e}=p \omega_{g}
\end{gathered}
$$

In (1)-(3), poles, electrical speed, stator resistance, generator inductances, magnetic flux, and leakage inductances are represented by $p, \omega_{e}, R_{s}, L_{d}, L_{q}, \psi_{f}, L_{i d}$, and $L_{i q}$, respectively. The $I_{d}$ and $I_{q}$ are PMSG current in direct and quadrature axis, respectively. Moreover, the electromechanical torque equation as shown in (4) is also employed in the PMSG model. 


$$
\tau_{e}=1.5 p\left(\left(L_{d s}+L_{i s}\right) i_{d} i_{q}+i_{q} \psi_{f}\right)
$$

Furthermore, the drive of wind turbine generator system is comprised of the rotor shaft, generator, blade pitching, and hub with the blade. In this paper, single-mass model is used to represent the wind turbine mechanical system. Therefore, the drive train model in this paper can be expressed as (5).

$$
\frac{d \omega_{g}}{d t}=\frac{\tau_{e}-\tau_{w_{-} g}}{J_{e q}}-\frac{B_{m}}{J_{e q}} \omega_{g}
$$

In (5), $\omega_{g}, B_{m}, \tau_{w_{-} g}, J_{e q}, \tau_{e}$ are mechanical speed of the generator, damping coefficient, aerodynamic torque, equivalent inertia, and electromechanical torque, respectively. In this research, rotor and grid side converter controllers are also modelled with mathematical representation. The full model of wind power system including the controller can be captured as given in Fig. 1 [11].

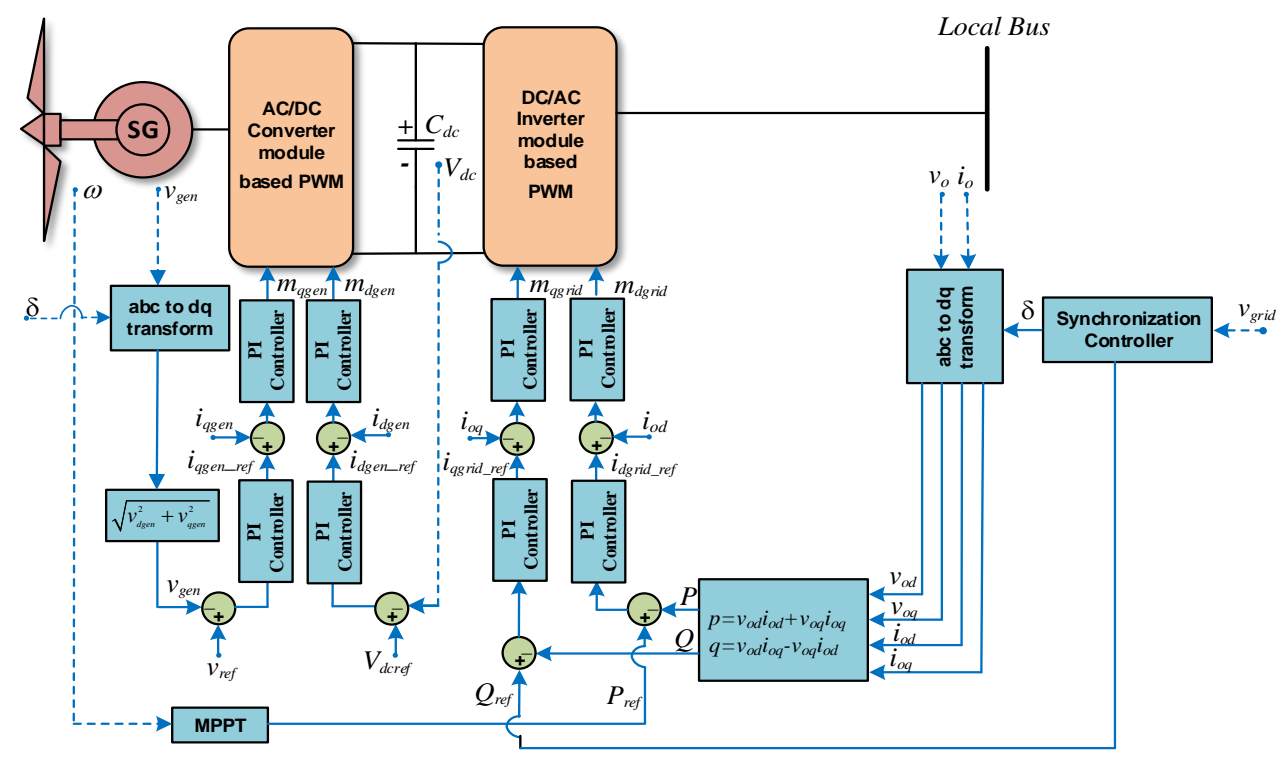

Figure 1. Schematic diagram of PMSG with the associated controller.

\section{B. PV Power System}

The North American Electric Reliability Corporation (NERC) and Western American Electricity Coordination Council (WECC) have developed a model of large-scale PV suitable for stability studies for the electromechanical time-frame [12, 13]. The dynamic model of PV plant developed by NERC and WECC consists of the converter and the associated controllers [13, 14]. The converter is represented by a set of first-order transfer function model. The converter controller consists of PI controller and current limiters. Furthermore, the MPPT dynamics including the DC link dynamics were not considered in this model [15]. The PV system is assumed to be operated around the maximum power point [15]. Fig. 2 shows the dynamic model of PV plant with multi-mode controller [13, 14]. 


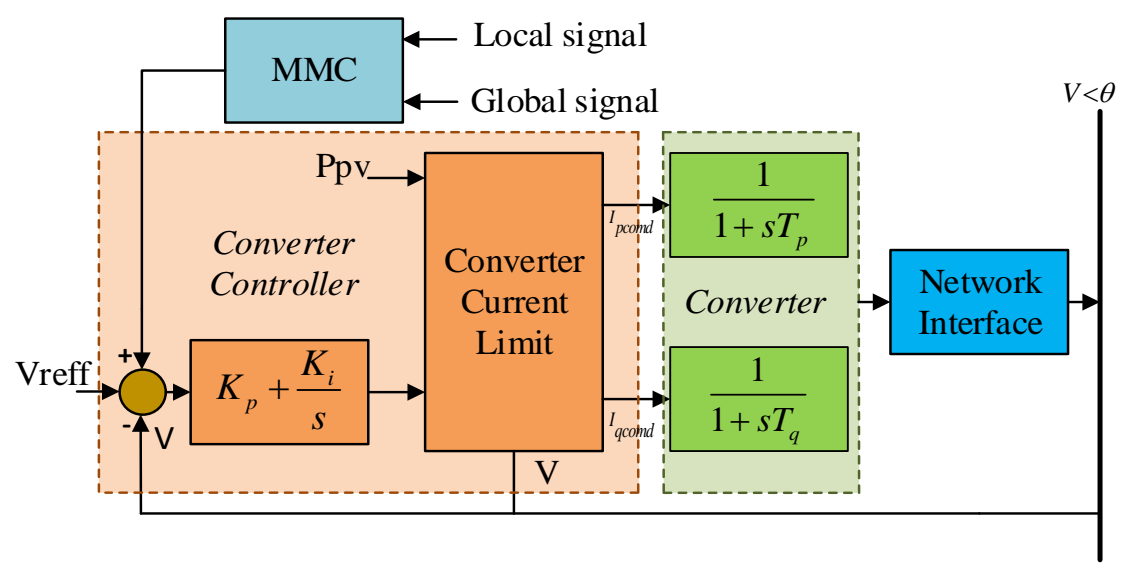

Bus

Terminal

Figure 2. PV plant with multi-mode controller.

In Fig 2, the multi-mode controller is added to the reactive power control block. Generally, the oscillation damping can be achieved by modulating the active power. However, due to the uncertainty of the PV source, the active power of PV is intermittent. Hence, the reactive power modulation method in PV is applied in this paper to damp the oscillation of critical mode [16].

The damping ratio of a mode is used to investigate how fast the oscillation can be damped. Based on the International Council on Large Electric Systems (CIGRE) the minimum damping ratio allowed in the power systems is in the range of 3\%-5\% [17]. However, without the loss of generality we choose the highest value, 5\%, in this paper. Hence, any mode with damping ratio lower than $5 \%$ is classified as the critical mode. Therefore, it is important to design the oscillation damping that could achieve this standard. Furthermore, designing the oscillation damping control itself has another standard that need to be fulfilled.

The WECC reported a standard regarding the oscillation damping in power systems. It states that the oscillation damping shall be set to provide the measured, simulated or calculated compensated the transfer function of voltage terminal divided by voltage reference $\left(V_{t} / V_{r}\right)$ in frequency domain of the excitation system such that the phase angle will not exceed \pm 30 degree for the frequency range from $0.2 \mathrm{~Hz}$ to $1 \mathrm{~Hz}[18]$.

\section{Battery Energy Storage Model}

The dynamic model of battery energy storage system (BESS) used in this research is adopted from [19]. This model consists of three phase ideal transformer, DC to AC converter, active and reactive power control dynamics, and battery dynamics. Fig. 3 shows the dynamic model of BESS with multi-mode controller. The multi-mode controller can be implemented in the firing angle of the converter so that the BESS could provide the required active and reactive power to the grid. For the simulation, a fifth order model of BESS is considered. The mathematical representation of BESS can be described using (6)-(12) [19].

$$
\begin{gathered}
\Delta P_{B E S S}=\frac{k_{B P}}{1+s T_{B P}} \Delta \omega \\
\Delta Q_{B E S S}=\frac{k_{B Q}}{1+s T_{B Q}} \Delta V_{t} \\
\alpha_{R}=\frac{k_{R}}{1+s T_{R}}\left(\alpha_{R}^{*}+k_{M} \Delta I_{B E S S}-U_{P O D}\right) \\
\alpha_{R}^{*}=\tan ^{-1}\left(\frac{Q_{B E S S}^{*}}{P_{B E S S}^{*}}\right) \\
V_{B O C}=\frac{R_{B P}}{1+s R_{B P} C_{B P}} I_{B E S S} \\
V_{B 1}=\frac{R_{B 1}}{1+s R_{B 1} C_{B 1}} I_{B E S S} \\
I_{B E S S}=\frac{1}{R_{B S}+R_{B T}}\left(V_{B T}-V_{B O C}-V_{B 1}\right)
\end{gathered}
$$

where $K_{B P}$ and $T_{B P}$ are the control loop gain and rotor speed measurement device time constant, respectively. While $K_{B Q}$ and $T_{B Q}$ are the control loop gain and terminal voltage measurement device time constant. Furthermore, $K_{R}$ and $T_{R}$ are the converter loop gain and the firing angle time delay constant. The $K_{M}$ and $I_{B E S S}$ are used to stabilize the BESS under constant current operation so 
that BESS can release more power from batteries. Moreover, $\boldsymbol{P}_{B E S S}^{*}$ and $Q_{B E S S}^{*}$ are active and reactive power output of converter controller. Furthermore, $R_{B P}$ and $C_{B P}$ are used to describe the resistance and capacitance self-discharge of a battery. While $R_{B I}$ and $C_{B 1}$ are the representation of energy and voltage during the charging and discharging. In (12), $V_{B O C}$ and $V_{B I}$ represent the battery open-circuit voltage and battery overvoltage, respectively. While, $V_{B T}, R_{B S}$, and $R_{B T}$ are the terminal voltage of the battery, series resistance of battery, and equivalent resistance of parallel/series connection of batteries [19].

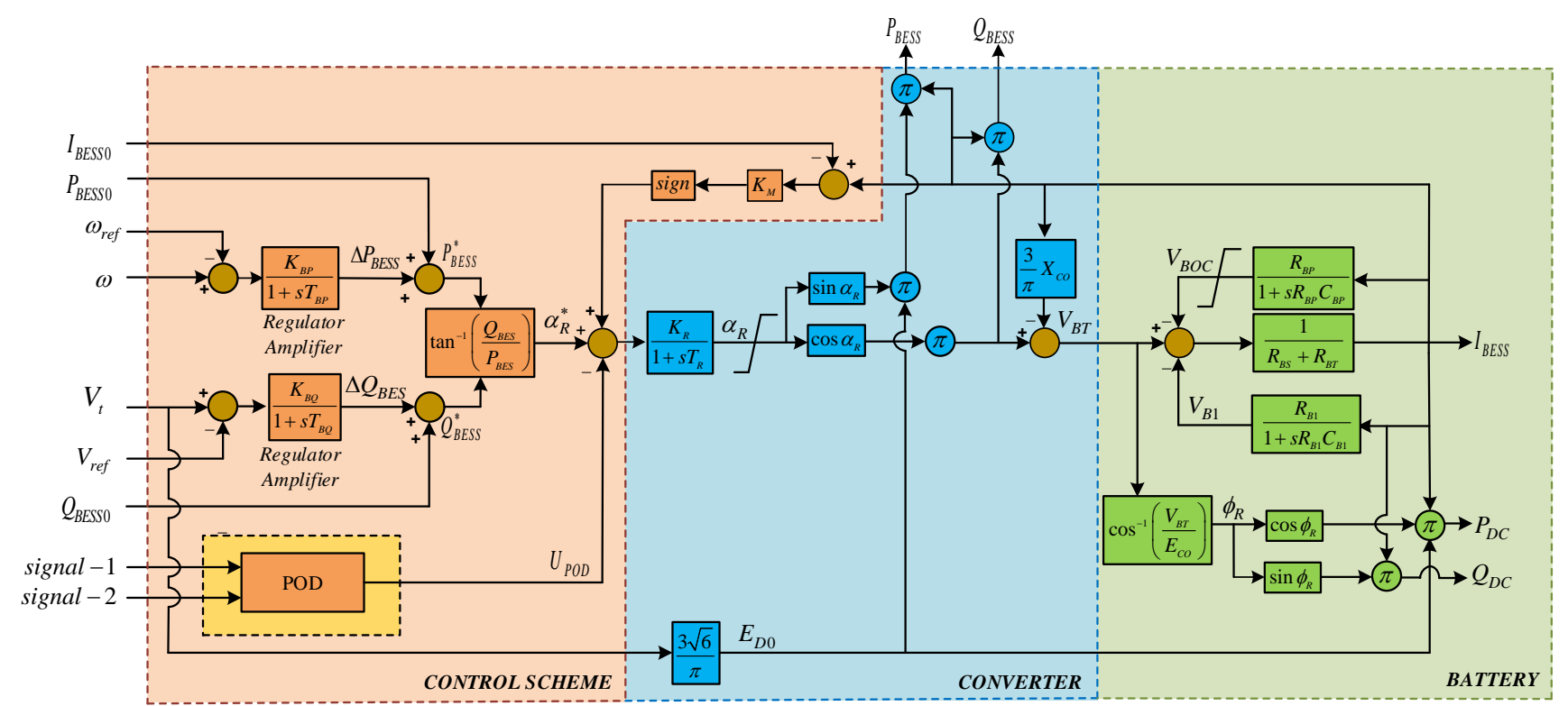

Figure 3. Dynamic model of BESS.

\section{Indices for Robustness Analysis}

The key indices to measure the non-linear response of power system are briefly explained in this section. To measure the nonlinear response of power system, integral squared error (ISE) and integral absolute error (IAE) are commonly used. The simulation time is not considered in the calculation of ISE and IAE. Hence, a new index called integral time absolute error (ITAE) can be used to measure the simulation time. All previously mentioned robustness indices are used in this paper to access the non-linear responses and performances of the power system. The mathematical representations of ISE, IAE, and ITAE can be captured by (13), (14), and (15) [20].

$$
\begin{gathered}
I S E=\int_{0}^{t i m e}(e(t))^{2} d t \\
I A E=\int_{0}^{t i m e}|e(t)| d t \\
I T A E=\int_{0}^{t i m e} t|e(t)| d t
\end{gathered}
$$

The transient kinetic energy (TKE) assessment has been used to further assess the robustness of power system. The mathematical model of TKE can be described using (16) [21].

$$
T K E=\sum_{i=1}^{n} \frac{1}{2} J_{i} \cdot \Delta \omega_{i}^{2}
$$

In (16), the angular momentum of the rotor at synchronous speed and speed deviation of $i^{\text {th }}$ generator in a system with $n$ machines are described as $J_{i}$ and $\Delta \omega_{i}$. 


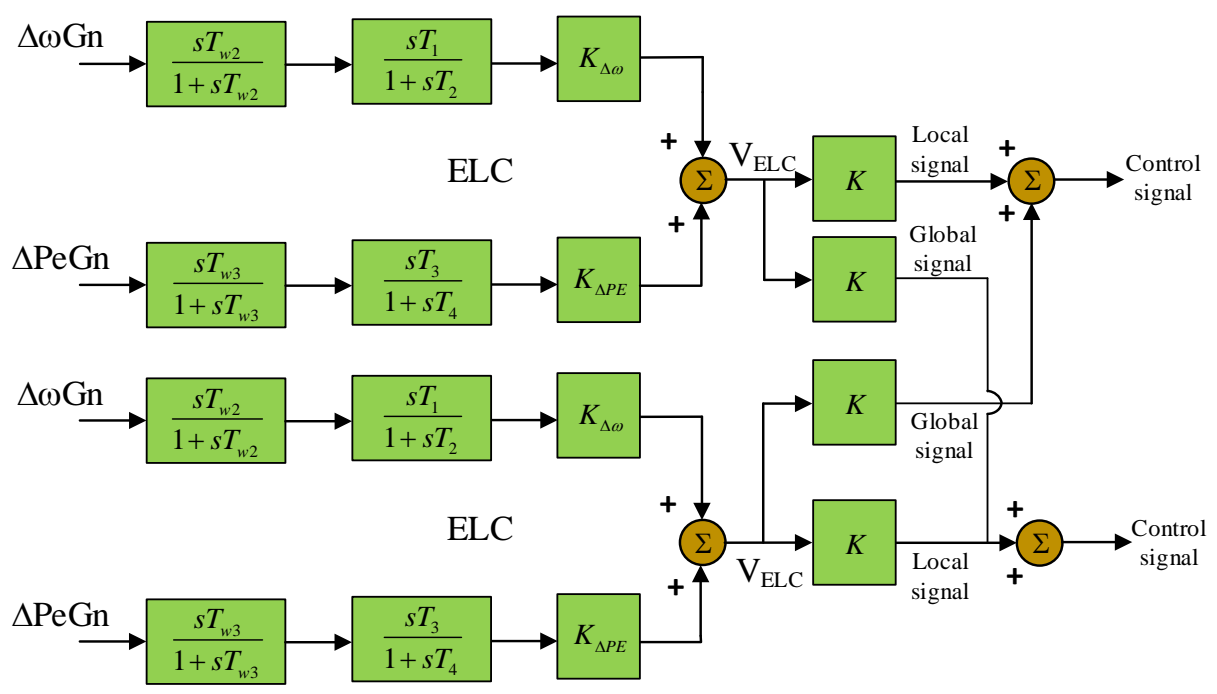

Figure 4. Multi-mode control structure.

\section{Controller Design}

\section{A. Multi-mode Controller}

The concept behind a multi-mode controller is to design multiple controllers to enhance the damping of specific weak modes. In this concept, when one of the controller is failed, the other controller can work as a backup. Furthermore, the general structure of this controller is multi-input multi-output. Therefore, this controller is also resilient to the communication failure as well. Fig. 4 illustrates the multi-mode controller (MMC) structure that is used in this paper.

As depicted in Fig.4, the MMC consists of the gain constant and external linear controller (ELC). The input of ELC is the rotor speed and electrical power of the generator that contribute to the weak modes. Moreover, the input of MMC is a combination of ELC output scaled by the gain constant. The output of MMC is a control signal to the BESS, wind, and PV power plant controller. In this paper, receiving and sending end time delays are also considered in the operation of the controller. Moreover, local and global time delays are considered with $100 \mathrm{~ms}$ and $700 \mathrm{~ms}$, respectively [22].

\section{B. Time Delay Model}

Two steps are used in the time delay to simulate the sending and receiving end signal latency. To capture the dynamic behaviour of time delay in the simulation, Padé approximation is used. The mathematical representation of time delay based on the Padé approximation can be described as (17) [22]:

$$
e^{-s T d}=\frac{1-K_{1} s+K_{2} s^{2}+\ldots \pm K_{n} s^{n}}{1+K_{1} s+K_{2} s^{2}+\ldots \pm K_{n} s^{n}}
$$

In (17), the constant coefficient and the order of approximation are described by $K_{1}, K_{2}, \ldots, K_{n}$, and $n$. Based on [22], the effect of first-order time delay and second-order time delay on the system performance are similar. Hence, in this paper the first-order time delay is used to represent the communication delay. To design the controller considering the time delay, an optimal algorithm should be used.

\section{Firefly Algorithm}

Firefly algorithm (FA) is inspired by flashing activity of fireflies.This flashing behaviour is acting as a signal to attract other fireflies. This algorithm was first introduced by Xin She Yang [23-26]. There are three important rules for modeling the FA as described below [23-26]:

- The fireflies should be attached to others fireflies regardless of their sex.

- The attractiveness should be proportional to the brightness of the fireflies.

- The objective function can be determined by the brightness of the firefly.

In this research, the degree of light intensity is influencing the attractiveness of the fireflies. The degree of light intensity of $x$ firefly can be described using (18) [23-26].

$$
I(x)=f(x)
$$

In (18), the objective function and light intensity of fireflies are indicated by $f(x)$ and $I$. Furthermore, the attractiveness coefficient that related to the light intensity is indicated by $\beta$. This attractiveness coefficient would be seen and assessed by other fireflies. Hence, the distance between the fireflies would have significant influence on the attractiveness coefficient. Furthermore, 
the light intensity will decrease due to the air factor $(\gamma)$. The air factor means the condition of the air in particular time. The air factor is modelled as constant value for this work. Hence, the attractiveness function can be mathematically represented as (19) [23-26].

$$
\beta(r)=\beta_{0} * \exp \left(-\gamma r^{m}\right),(m \geq 1)
$$

The distance between fireflies can be determined when all of the fireflies are randomly dispersed in the Cartesian diagram. The mathematical representation of the distance between different fireflies can be described as given in (20). Where, $r_{i j}$ is the distance between firefly $i$ to firefly $j$ [23-26].

$$
r_{i j}=\sqrt{\left(x_{i}-x_{j}\right)^{2}+\left(y_{i}-y_{j}\right)^{2}}
$$

In (21), the initial position of fireflies at $x$ location and variable that has value in the range of 0 to 1 are $x_{i}$ and $\alpha$ [21].

$$
x_{i}=x_{i}+\beta_{0} * \exp \left(-\gamma r_{i j}^{2}\right) *\left(x_{j}-x_{i}\right)+\alpha *\left(\operatorname{rand}-\frac{1}{2}\right)
$$

\section{Objective Function}

In this paper, FA is used as the optimization method for designing wide-area multi-mode controller for BESS, wind, and PV plant controller. Multi-objective function is used in this paper. The objective function of FA can be described as (22).

$$
\text { Objective }=\min \left(a Z_{1}+b Z_{2}+c Z_{3}\right)
$$

In (22), $\mathrm{Z}$ are the mathematical equation that can be described by (23), (24), and (25). The real parts of the $i^{\text {th }}$ mode and the desired location of the mode are described by $\sigma_{i}$ and $\sigma_{0}$. Furthermore, the damping value of the $i^{\text {th }}$ eigenvalue and the desired damping value are presented by $\xi_{i}$ and $\xi_{0}$. Moreover, the oscillatory responses of generator rotor speed, MMC parameter, and the time frame simulation are described by $\Delta \omega(t, X), X, t_{1}$. The weighting factors are in the range of 0 to 1 presented as $a, b$, and $c$.

$$
\begin{gathered}
Z_{1}=\sum_{\sigma_{0} \geq \sigma_{i}}\left[\sigma_{0}-\sigma_{i}\right]^{2} \\
Z_{2}=\sum_{\xi_{0} \leq \xi_{i}}\left[\xi_{0}-\xi_{i}\right]^{2} \\
Z_{3}=\sum \int_{0}^{t_{1}} t|\Delta \omega(t, X)| d t
\end{gathered}
$$

Subject to:

$$
\begin{aligned}
& 10 \leq T_{W 2}, T_{W 3} \leq 20 \\
& 0.05 \leq T_{1} \leq 0.1 \\
& 0.02 \leq T_{2} \leq 0.1 \\
& 0.03 \leq T_{3} \leq 0.1 \\
& 0.01 \leq T_{4} \leq 0.1 \\
& 5 \leq K_{\Delta \omega n} \leq 20 \\
& 1 \leq K_{\Delta p e n} \leq 2 \\
& 50 \leq K_{n} \leq 100
\end{aligned}
$$

The parameter bounds are selected based on the IEEE recommendation standard [27] (see Appendix section for parameter values of the controller). The concept applied here is to use the stochastic approach to determine the parameters of MMC. The MMC parameters are explained in Fig. 4. The upper and lower limits of parameters for MMC are given in Eq. 26. The stochastic approach for tuning MMC parameter is carried out by the firefly algorithm method. The simple pseodo code of this algorithm can be seen in the Appendix. 


\section{Results And Discussions}

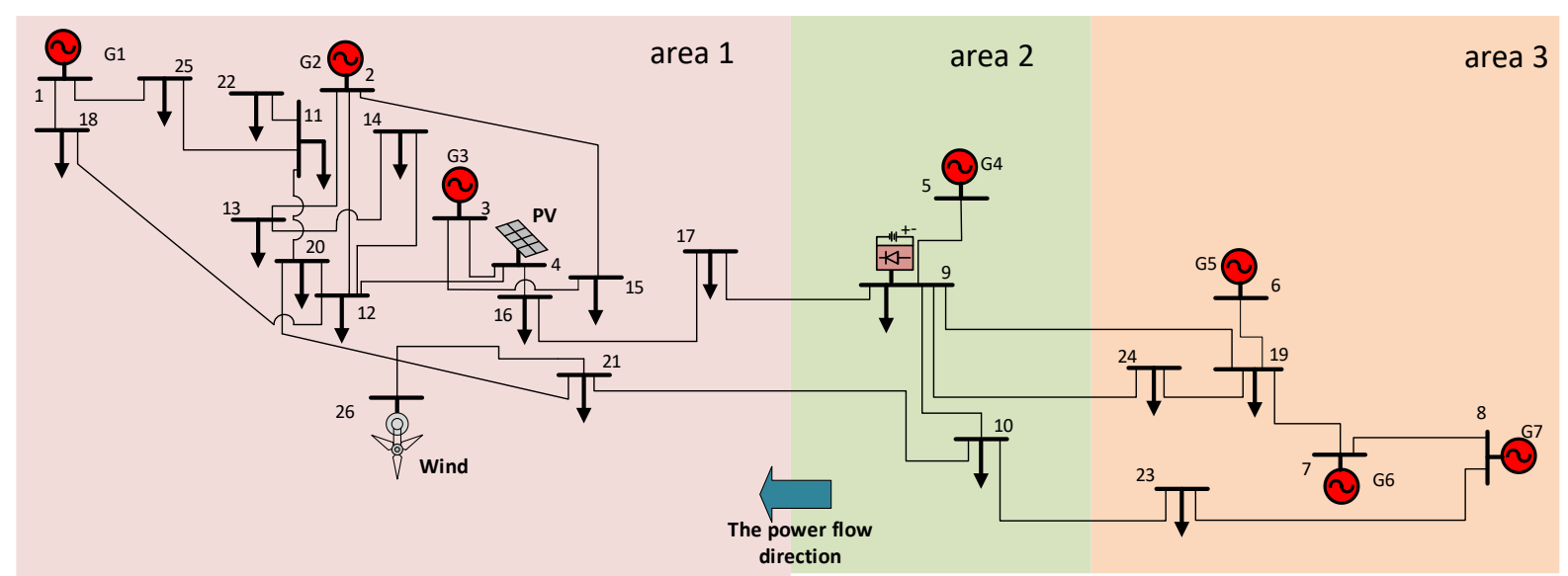

Fiqure 5. Java Indonesian power arid.

The $500 \mathrm{kV}$ Java-Indonesian electric grid has been considered in this paper to demonstrate the efficacy of the proposed controller. The machine parameters as well as the power flow are taken from the realistic operating conditions of the JavaIndonesian electric grid. To simulate the future power system in Indonesia (60\% from the conventional generator and $40 \%$ from renewable-based generation [27]), renewable power generations are considered in the Java grid. A 300 MW large-scale PV plant is replaced a synchronous generator in area 1 (at bus 4). Moreover, a $300 \mathrm{MW}$ aggregated wind farm is also integrated in area 1. Furthermore, 100 MW BESS is also added to the bus 9 in area 2 as shown in Fig. 5. All of the renewable power generation plants in this studied system are considered to be operated at the maximum power point. Table I shows the electromechanical mode of the modified Java-Indonesian electric grid. The system consists of six local and one inter-area modes. Among the modes, the interarea and one of the local modes (i.e. local mode 2) demonstrate lower damping (damping ratio lower than the industry standards). From the initial studies, it is evident that the G3 and G4 are contributing significantly to these modes. Henceforth, the rest of the paper focuses on these two modes only.

TABLE I

DAMPING PERFORMANCE OF JAVA-INDONESIAN GRID

\begin{tabular}{ccc}
\hline Mode & Damping & $\begin{array}{c}\text { Participation of the } \\
\text { generator }\end{array}$ \\
\hline Inter-area & 0.00207 & $\mathrm{G} 3, \mathrm{G} 4$ \\
Local 1 & 0.00907 & $\mathrm{G} 5$ \\
Local 2 & 0.00211 & $\mathrm{G} 4$ \\
Local 3 & 0.00626 & $\mathrm{G} 1$ \\
Local 4 & 0.00625 & $\mathrm{G} 2$ \\
Local 5 & 0.2684 & $\mathrm{G} 6, \mathrm{G} 7$ \\
Local 6 & 0.1809 & $\mathrm{G} 7, \mathrm{G} 6$ \\
\hline
\end{tabular}

To investigate the performance of the system with the proposed control method, four different scenarios are considered. Table II illustrates the four different scenarios used in this paper. First, the modal analysis and time-domain simulation are performed. In this analysis, the comparisons of damping performance in four different scenarios are performed. Moreover, the non-linear timedomain simulations are conducted to validate the results. Furthermore, the resiliency of the controller is investigated. In this section, the different condition is applied to the system to determine the resiliency of the controller. Finally, the maximum RES penetration level for the Indonesian grid from the oscillatory stability point of view is determined.

TABLE II

SCENARIOS FOR SIMULATION STUDIES

\begin{tabular}{cl}
\hline Scenario & \multicolumn{1}{c}{ Remarks } \\
\hline $\mathbf{1}$ & $\begin{array}{l}\text { Modified Java system (Java system with PV, } \\
\text { wind, and BESS) } \\
\text { Modified Java system with the conventional wide- } \\
\text { area POD located at wind, PV, and BESS }\end{array}$ \\
$\mathbf{2}$ & $\begin{array}{l}\text { Modified Java system with resilient wide-area } \\
\text { MMC located at wind, PV, and BESS using other } \\
\text { methods } \\
\text { Modified system with resilient wide-area MMC } \\
\text { using FA at BESS, PV, and wind }\end{array}$ \\
\hline
\end{tabular}




\section{A. Numerical Results}

This section is focuses on modal analysis of the Java Indonesian power grid with different scenarios. This analysis can be done by investigating the damping performance of the system. In this paper, only local mode 2 and inter-area mode are investigated since these are identified as the critical modes in the Indonesian grid by the eigenvalue analysis. Fig. 6 illustrates the damping ratio comparison under different scenarios. It is evident that the best damping performance is observed in Scenario 4. This could have happened because of BESS, wind, and PV produces appropriate active and reactive power to the grid with proposed MMC designed using FA. To validate the damping performance analysis, time-domain simulations are carried out. To observe the oscillatory condition of the system, a small disturbance is made in the system by changing the load ( 0.01 step input to the load). Fig. 7 shows the comparison of the oscillatory condition of the rotor speed of G3 under four different scenarios. While Fig. 8 illustrates the rotor speed responses of G4 under different scenarios. Furthermore, the results in Tables III and IV show the detailed features of settling time and overshoot of G3 and G4. It is observed that the system experiences the best-damped response when the proposed controller is applied to the system.

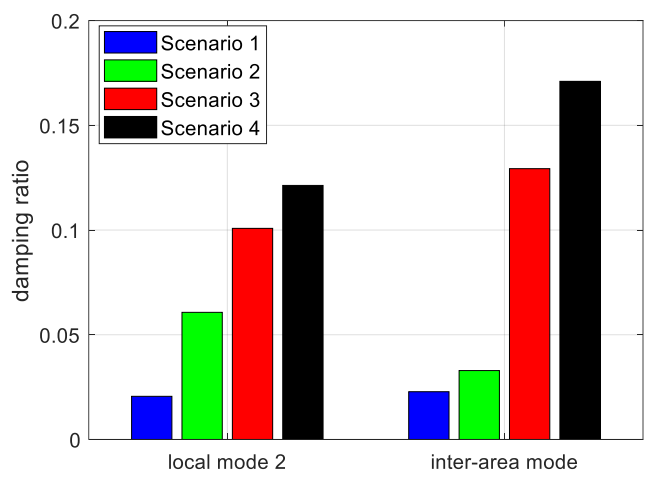

Figure 6. Damping performance comparison under different scenarios.

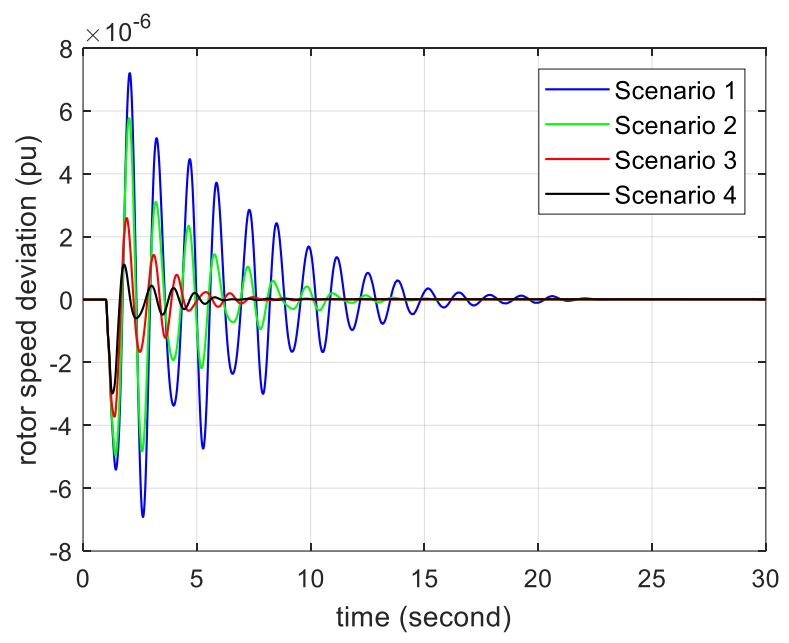

Figure 7. Rotor speed responses of G3.

TABLE III

\begin{tabular}{lcccc}
\multicolumn{5}{c}{ DETAILED FEATURES OF G3 } \\
\cline { 1 - 5 } Scenarios & $\mathbf{1}$ & $\mathbf{2}$ & $\mathbf{3}$ & $\mathbf{4}$ \\
\hline $\begin{array}{l}\text { Overshoot } \\
\text { Settling }\end{array}$ & $-5.41 \times 10^{-6}$ & $-4.96 \times 10^{-6}$ & $-3.73 \times 10^{-6}$ & $-2.99 \times 10^{-6}$ \\
time & $>30$ & $>15$ & $<10$ & $<5$ \\
\hline
\end{tabular}

TABLE IV

\begin{tabular}{lcccc}
\multicolumn{5}{c}{ DETAILED FEATURES OF G4 } \\
\hline \hline Scenarios & $\mathbf{1}$ & $\mathbf{2}$ & $\mathbf{3}$ & $\mathbf{4}$ \\
\hline $\begin{array}{l}\text { Overshoot } \\
\text { Settling }\end{array}$ & $-9.06 \times 10^{-6}$ & $-8.69 \times 10^{-6}$ & $-6.59 \times 10^{-6}$ & $-5.73 \times 10^{-6}$ \\
time & $>30$ & $>15$ & $<10$ & $<10$ \\
\hline
\end{tabular}




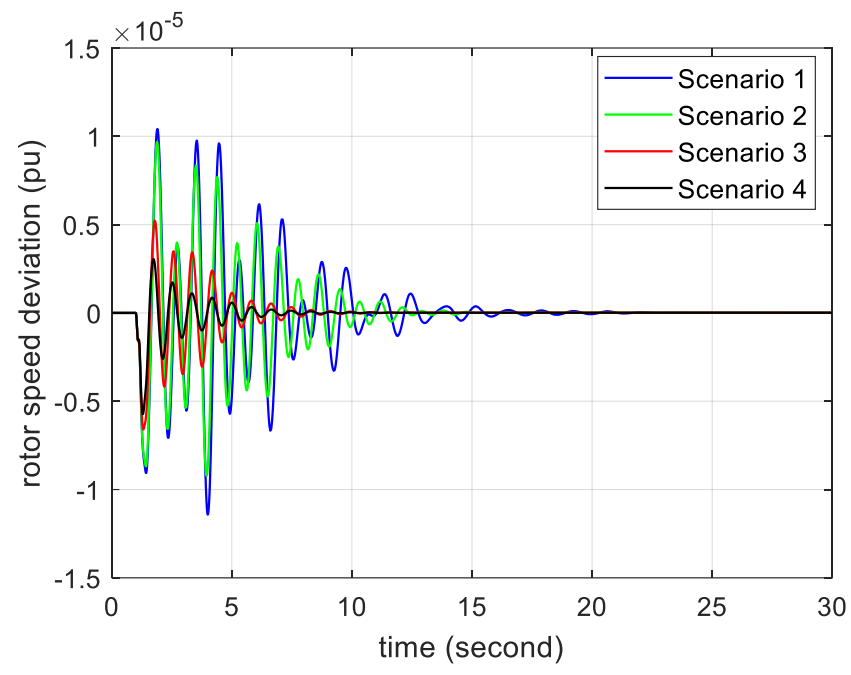

Figure 8: Rotor speed responses of G4.

\section{B. Robustness Analysis}

In this section, the four scenarios are compared using IAE, ISE, and ITAE criterion assessment. The purpose of this assessment is to check the error in system non-linear time-domain responses. Only the rotor speed of G3 and G4 are assessed as they contribute to oscillation modes. Moreover, rotor speed represents the electromechanical oscillation of the system. The damping condition associated with the rotor speed G3 and G4 is represented by the minimum error in non-linear time domain simulation. Hence, the electromechanical oscillation of G3 and G4 are also enhanced when rotor speed oscillation of G3 and G4 are damped. The comparisons of IAE, ISE, and ITAE under different scenarios are given in Tables V and VI. It is worth noting that the lesser the value of IAE, ISE, and ITAE is better. As shown in Table V and VI, the smallest value for all three indices are achieved for scenario 4 (i.e. MMC controller desiged using FA).

Furthermore, the four scenarios are also compared by using TKI index. The purpose of this test is to investigate the robustne ss of the system with the proposed MMC. Table VII illustrates the TKE for G3 and G4 under different scenarios. It can be seen that the lowest TKE value for G3 and G4 are provided by scenario 4. From the simulation results, it can be stated that by using the proposed controller, the system does not have to relay on high kinetic energy when a disturbance occurs. Hence, the stability of the system could also be enhanced.

TABLE V

IAE, ISE AND ITAE FOR G3 ROTOR SPEED RESPONSES

\begin{tabular}{lllll}
\hline \hline Case & Scenario 1 & Scenario 2 & Scenario 3 & Scenario 4 \\
\hline ITAE & $28.87 \times 10^{-2}$ & $27.66 \times 10^{-4}$ & $42.39 \times 10^{-6}$ & $13.51 \times 10^{-6}$ \\
IAE & $11.21 \times 10^{-3}$ & $14.74 \times 10^{-5}$ & $10.06 \times 10^{-6}$ & $51.93 \times 10^{-7}$ \\
ISE & $18.12 \times 10^{-6}$ & $10.77 \times 10^{-10}$ & $17.27 \times 10^{-12}$ & $79.65 \times 10^{-13}$ \\
\hline
\end{tabular}

TABLE VI

IAE, ISE AND ITAE FOR G4 ROTOR SPEED RESPONSES

\begin{tabular}{lllll}
\hline \hline Case & Scenario 1 & Scenario 2 & Scenario 3 & Scenario 4 \\
\hline ITAE & $25.34 \times 10^{-2}$ & $43.53 \times 10^{-4}$ & $41.81 \times 10^{-6}$ & $15.45 \times 10^{-6}$ \\
IAE & $98.6 \times 10^{-3}$ & $22.65 \times 10^{-5}$ & $85.64 \times 10^{-6}$ & $43.83 \times 10^{-7}$ \\
ISE & $13.84 \times 10^{-6}$ & $26.36 \times 10^{-10}$ & $99.17 \times 10^{-12}$ & $38.83 \times 10^{-13}$ \\
\hline
\end{tabular}

TABLE VII

TKI VALUES FOR VARIOUS SCENARIOS

\begin{tabular}{ccccc}
\multicolumn{5}{c}{ TKI VALUES FOR VARIOUS SCENARIOS } \\
\hline \hline Scenarios & $\mathbf{1}$ & $\mathbf{2}$ & $\mathbf{3}$ & $\mathbf{4}$ \\
\hline G3 & $22 \times 10^{-11}$ & $19 \times 10^{-11}$ & $10 \times 10^{-11}$ & $67 \times 10^{-12}$ \\
G4 & $62 \times 10^{-11}$ & $57 \times 10^{-11}$ & $32 \times 10^{-11}$ & $25 \times 10^{-11}$ \\
& & & & \\
\hline
\end{tabular}

Moreover, the performance of the proposed method is assesed for several operating conditions by considering different load and generation capacities. As reported in [29], small changes in the operating condition could affect the oscillatory condition of power system. Table VIII shows the different operating conditions assessed in this paper. While Table IX illustrates the system performance of scenario 4 under the different operating conditions. 
TABLE VIII

DIFFERENT OPERATING CONDITION FOR JAVA SYSTEM

\begin{tabular}{|c|c|}
\hline Scenario & Remarks \\
\hline OC 1 & $\begin{array}{l}\mathrm{G}_{1} \text { output is } 1605.8 \mathrm{MW} \text { and load demand in bus } \\
18 \text { and } 25 \text { are } 499 \mathrm{MW} \text { and } 396 \mathrm{MW}\end{array}$ \\
\hline OC 2 & $\begin{array}{l}\mathrm{G}_{2} \text { output is } 1540 \mathrm{MW} \text { and load demand in bus } 14 \\
\text { and } 12 \text { are } 1249 \mathrm{MW} \text { and } 733.7 \mathrm{MW}\end{array}$ \\
\hline OC 3 & $\begin{array}{l}\text { Load demand in bus } 15,16,17 \text { and } 21 \text { are } 1296 \\
\text { MW, 536.6 MW, 329.6 MW and } 149.6 \mathrm{MW}\end{array}$ \\
\hline OC4 & $\begin{array}{l}\text { Load demand in bus } 11,13,20 \text { and } 22 \text { are } 915 \\
\text { MW, } 810 \mathrm{MW}, 384 \mathrm{MW} \text { and } 227.3 \mathrm{MW}\end{array}$ \\
\hline OC 5 & $\begin{array}{l}\text { Load demand in bus } 11,12,13,14,15,16,17,18 \text {, } \\
20,21,22 \text { and } 25 \text { are } 865 \mathrm{MW}, 683 \mathrm{MW}, 760 \\
\mathrm{MW}, 1099 \mathrm{MW}, 1146 \mathrm{MW}, 486 \mathrm{MW}, 279 \mathrm{MW}, \\
449 \mathrm{MW}, 334 \mathrm{MW}, 149.5 \mathrm{MW}, 227 \mathrm{MW} \text {, and } 396 \\
\text { MW }\end{array}$ \\
\hline
\end{tabular}

It is found that the damping performance of the system in scenario 4 are well above 0.05 (which is the minimum damping ratio expected by industry) under different operating conditions. From this results, it can be stated that the proposed controller is robustly stable under different operating condition.

TABLE IX

DAMPING PERFORMANCE UNDER DIFFERENT OPERATING CONDITION

\begin{tabular}{ccc}
\hline \hline Mode & Local 2 & Inter-area \\
\hline OC 1 & 0.1061 & 0.1563 \\
OC 2 & 0.0740 & 0.1683 \\
OC 3 & 0.0738 & 0.1710 \\
OC 4 & 0.0739 & 0.1705 \\
OC 5 & 0.0737 & 0.1710 \\
\hline
\end{tabular}

\section{Resilient Tests}

As shown in Figs. 7 and 8, the proposed controller is superior compared to others. Hence, in this section, the resiliency of the controller is tested. The resiliency of the controller is tested by disabling the wide-area signals. Moreover, the resiliency of the controller is also tested by disabling one of the controllers in the proposed MMC.

Table $\mathrm{X}$ shows the damping fluctuation of critical mode due to the resiliency test. It is found that the damping performance of local mode 2 and inter-area mode are decreased when communication and controller failures occurred. The worst condition is provided when controller failure emerges at wind and BESS locations simultaneously. However, even in the worst condition, the damping performance is higher than the threshold value used in the utility industries (i.e. 0.05 p.u.). Furthermore, from this study, it can be stated that wind and BESS could provide a better damping then the PV plant. Moreover, according to Table X, the proposed controller is robustly stable against communication and controller failures.

TABLE X

RESILIENT TEST RESULTS

\begin{tabular}{|c|c|c|}
\hline Case & Local 2 & Inter-Area \\
\hline Normal condition & 0.1710 & 0.1213 \\
\hline Loss of signals & 0.1685 & 0.0775 \\
\hline BESS controller failure & 0.1181 & 0.0629 \\
\hline WECS controller failure & 0.0846 & 0.0631 \\
\hline PV controller failure & 0.1284 & 0.0649 \\
\hline $\begin{array}{l}\text { WECS and PV controller } \\
\text { failure }\end{array}$ & 0.0631 & 0.0635 \\
\hline $\begin{array}{l}\text { PV and BESS controller } \\
\text { failure }\end{array}$ & 0.0866 & 0.0624 \\
\hline $\begin{array}{l}\text { WECS and BESS } \\
\text { controller failure }\end{array}$ & 0.0563 & 0.0571 \\
\hline
\end{tabular}




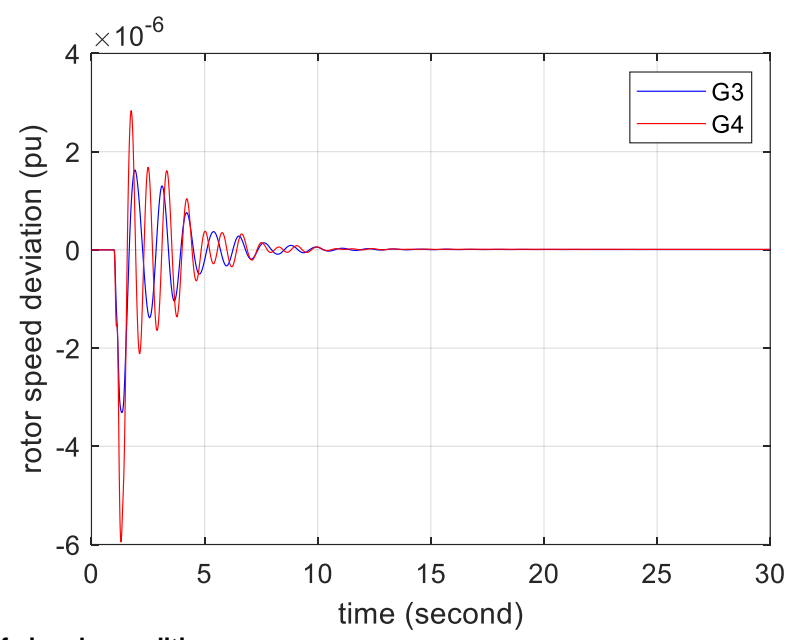

Figure 9. Rotor speed responses under loss of signals condition.

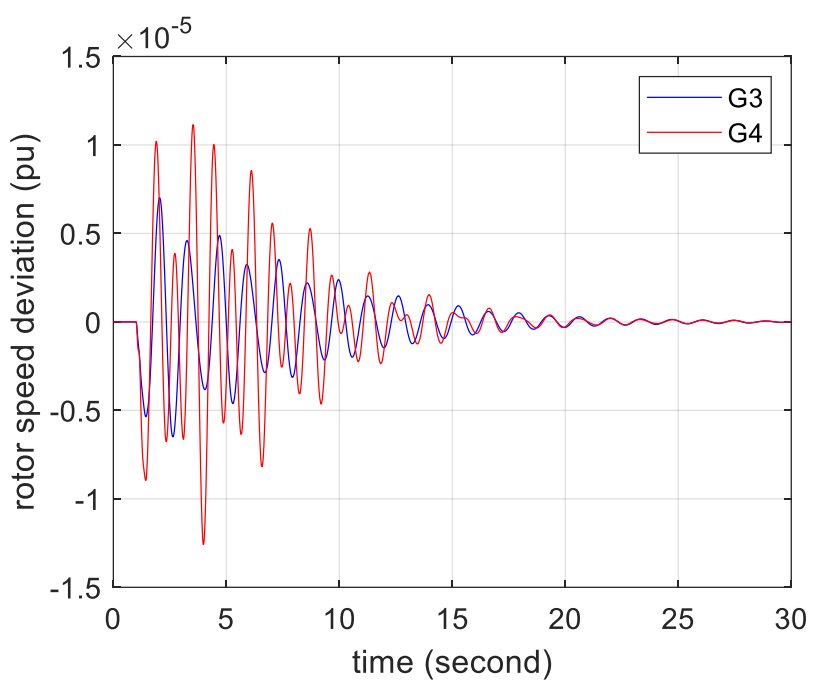

Figure 10. Rotor speed responses under WECS and BESS controller failure.

Fig. 9 illustrates the rotor speed responses under the loss of signals. While, Fig. 10 shows the rotor speed responses of G3 and G4 under controller failures in WECS and BESS. It is noticeable that the response of system under controller failure have more oscillations than system with loss of signals condition. Moreover, the results given in Fig. 9 and Fig. 10 validated the eigenvalue assessment results given Table $\mathrm{X}$.

\section{Impact of Increasing RESs}

The impact of various penetration of RESs on oscillatory stability is investigated next. The penetration of RESs is varied from $6 \%$ to $50 \%$ of the total system generation. The damping performance is used to estimate how much RESs can be integrated into the Java - Indonesian power system from the oscillator stability point of view. Results in Tables XI and XII show the comparison of damping of inter-area and local mode 2 due to the increasing penetration of RESs under different scenarios. It is found from Tables XI and XII that the damping of inter-area mode are deteriorated when the penetration of RESs are increased. This may have happened due to the following reasons:

- Lower total inertia in the system.

- Change in overall power flow direction.

- Different dynamic characteristics of RESs.

It can be observed that the percentage damping of inter-area mode becomes negative for scenario 2 when penetration of RESs increased by more than 35\%. It also noticeable that the damping of inter-area mode for scenario 2 is below the industry requirements even when the penetration of RESs is only 6\%. Furthermore, the damping performance of scenario 3 becomes less than the minimum standard when the penetration of RESs are increased by more than $30 \%$. Moreover, the damping performance becomes less than the industry requirement when the RESs are increased beyond 50\% for scenario 4 . It is also observed that for local mode 2 the damping performance for scenario 2 will not experience negative damping even the RESs are increased up to 50\%. However, the damping value will fall under the industry requirement when the RESs are increased by more than $25 \%$. Furthermore, it is also observed that both local mode 2 damping performance for scenarios 3 and 4 are still above the minimum standard even with RESs 
up to $50 \%$. However, in an oscillatory stability point of view, damping of all of the EM modes should exceed $5 \%$ standard. Hence, based on the simulations, it is evident that only scenario 4, i.e. the system with proposed controller desiged using FA is suitable for the future Indonesian power grid.

TABLE XI

DAMPING PERFORMANCE OF INTER-AREA MODE WITH HIGH RESS

\begin{tabular}{llll}
\hline \hline Case & Scenario 2 & Scenario 3 & Scenario 4 \\
\hline $\mathbf{6 \%}$ & 3.29 & 10.08 & 12.13 \\
$\mathbf{1 0 \%}$ & 3.12 & 9.13 & 11.74 \\
$\mathbf{2 0 \%}$ & 2.78 & 7.77 & 11.05 \\
$\mathbf{3 0 \%}$ & 1.91 & 5.35 & 9.34 \\
$\mathbf{4 0 \%}$ & -1.79 & 3.12 & 5.81 \\
$\mathbf{5 0 \%}$ & -2.12 & 2.11 & 5.00 \\
\hline
\end{tabular}

TABLE XII

DAMPING PERformanCE OF LOCAL MOdE 2 WITH High RESS

\begin{tabular}{llll}
\hline \hline Case & Scenario 2 & Scenario 3 & Scenario 4 \\
\hline $\mathbf{6 \%}$ & 6.07 & 12.93 & 17.10 \\
$\mathbf{1 0 \%}$ & 5.70 & 11.16 & 16.78 \\
$\mathbf{2 0 \%}$ & 5.04 & 10.32 & 15.59 \\
$\mathbf{3 0 \%}$ & 4.83 & 9.76 & 14.25 \\
$\mathbf{4 0 \%}$ & 4.22 & 8.16 & 13.99 \\
$\mathbf{5 0 \%}$ & 4.11 & 7.00 & 12.11 \\
\hline
\end{tabular}

\section{E. Comparisons of Different Methods}

The proposed metaheuristic method (scenario 4) is compared with other well-known metaheuristic methods (particle swarm optimization and bat algorithm) to assess the effectiveness of the method. Fig. 11 shows the comparison of execution time between proposed metaheuristic method compared with particle swarm optimization (PSO) and bat algorithm (BA). It is found that the execution time of the proposed method is faster compared to other methods. If the size and complexity of the system increased, the execution time is also expected to increase,thereby, it is recommended to use the algorithm with lower execution time.

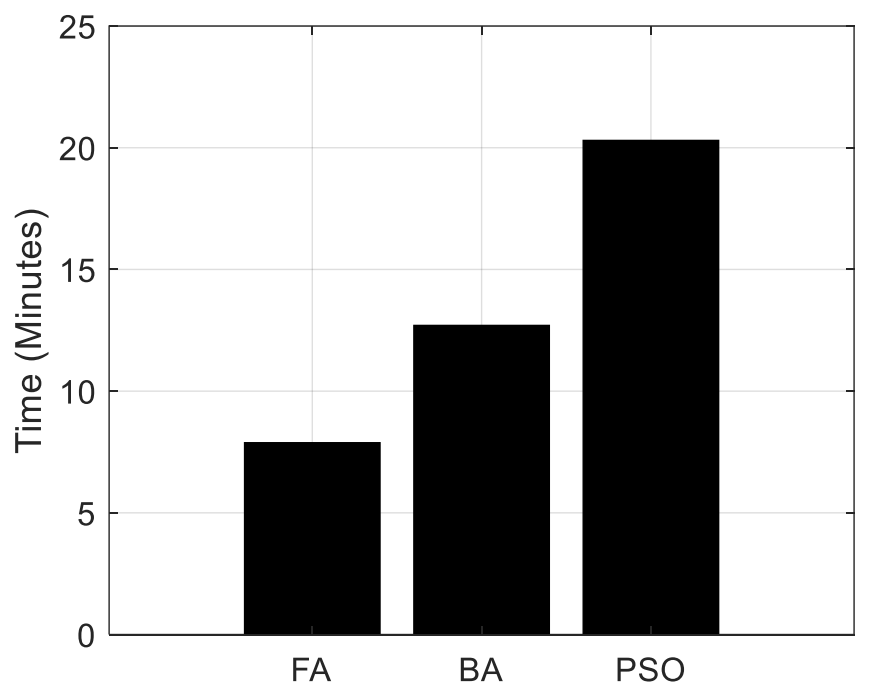

Figure 11: Comparison of execution time.

The ranking index given in [10] has been used to assess the performance of the proposed controller. Three different ranks are used in this study. Those three different ranks are the performance rank, robustness rank, and simplicity rank. The mathematical representation of this controller performance rank is described in appendix. Fig. 12 illustrates the controller performance rank comparison between proposed metaheuristic method and other metaheuristic methods. It is noticeable that the proposed metaheuristic method is superior (the value is near to 1) in all three ranks compared with PSO and BA. It should be worth noting that all methods exhibit poor performance against the satisfactory ranking. 
Figure 12: Controller rank comparison.

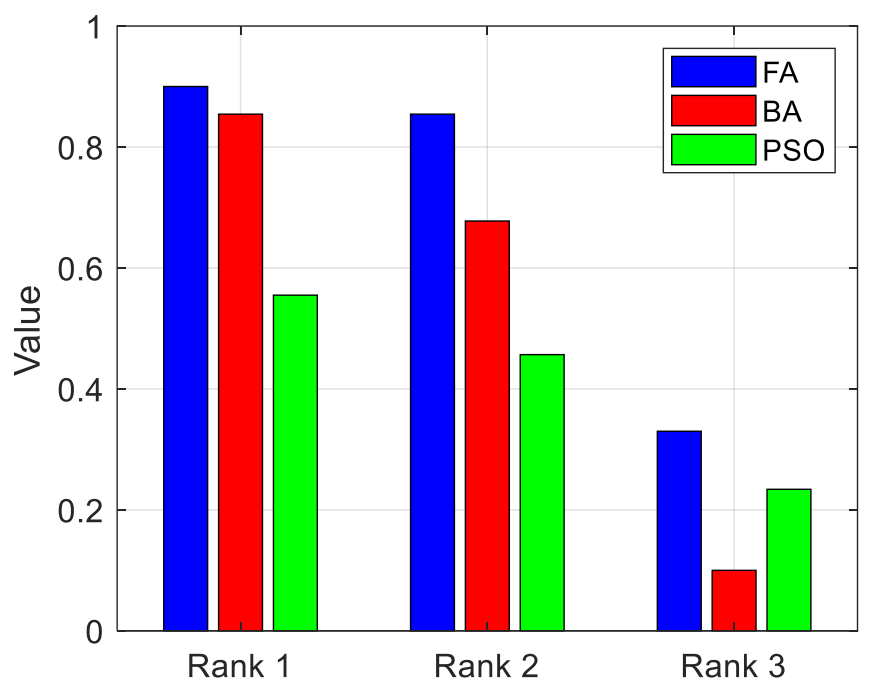

\section{Conclusions}

Resilient wide-area multi-mode controller (MMC) based on FA is proposed and appraised in this paper. The coordinated controller is designed for BESS, wind, and PV system. The efficacy of the proposed method is tested in a representative realistic power system model (i.e. Java Indonesian system). A modification has been made in the system by integrating large-scale WPP, PV, and BESS to simulate the future scenarios of the Indonesian grid. From the case studies, it is evident that the proposed resilient wide-area MMC can maintain satisfactory damping under communication and control failures. Moreover, the proposed control method has advantages over other controllers in terms of TKE, IAE, ISE, and ITAE. It should be noted that the proposed control method is also able to provide a satisfactory damping ratio under severe communication and controller failures under different renewable energy penetration levels. Moreover, the renewable energy penetration in the Java power system can be enhanced up to $50 \%$ with the proposed multi-mode controller.

\section{APPENDIX}

The controller rank indices used in this paper are given next. The controller rank index consists of three different measurements. The first measurement is the performance (described by Eq. 27), the second measurement is the robustness (described by Eq. 28), and the last measurement is simplicity (described by Eq. 29) [30].

$$
\begin{aligned}
& R^{\text {Per }}=w^{\xi} N\left[\xi^{\text {Contr }}-\xi^{\text {Base }}\right]+w^{\tau} N\left[\tau^{\text {Contr }}-\tau^{\text {Base }}\right] \\
& +w^{\Delta \omega} N\left[\Delta \omega^{\text {Contr }}-\Delta \omega^{\text {Base }}\right]
\end{aligned}
$$

In (27), $w^{\xi}, w^{\tau}$, and $w^{\Delta \omega}$ are weighting factors for the damping, settling time, and overshoot of the rotor speed. The value of weighting factors are respectively $0.4,0.4$, and 0.2 . The $N$ indicates the normalization of these factors. The normalization factors is used to make sure that all the observed parameters have values ranging from 0 to 1 . The Contr and Base superscripts indicate the system with controller and base condition, respectively [30].

$$
\begin{aligned}
& R^{\text {rob }}=w^{\text {all }} N\left[\frac{1}{M} \sum_{1}^{M}\left(\xi^{\text {Contr }}-\xi^{\text {Base }}\right)\right] \\
& +w^{\min } N\left[\xi_{\text {min }}^{\text {Contr }}-\xi_{\min }^{\text {Base }}\right]
\end{aligned}
$$

In (28), $w^{\text {all }}$ and $w^{\text {min }}$ are the weighting factor for all condition and the minimum damping comparison with 0.5 as the value of each weighting factor. While $M$ indicates the number of operating conditions and the subscript min related to the operating condition with the minimum damping enhancement is achieved [30].

$$
\begin{aligned}
& R^{\text {sim }}=w^{t} N\left[\left(t^{\text {Contr }}\right)^{-1}\right]+w^{c} N\left[\left(t^{\text {Code }}\right)^{-1}\right] \\
& +w^{p} N\left[p^{\text {Contr }}\right]
\end{aligned}
$$


In (29), $t^{\text {Cour }}, t^{\text {Code }}$, and $p^{\text {Contr }}$ are controller tuning time, number of code lines, and personal scores related to the simplicity. The weighting factors of tuning time, number of code lines, and personal score are indicated by $w^{t}, w^{t}$ and $w^{t}$ with value $0.4,0.4$ and $0.2[30]$.

The firefly algorithm pseudo code for optimizing MMC parameters is given below:

Firefly algorithm pseudo code

1. Initialize parameter: iteration, $\gamma, \beta, \alpha, D, n$

/* $\alpha$ value varies between 0 to $1 * /$

$1 * \mathrm{D}$ is the dimension of the solution*/

/* $\gamma$ value varies between 0 to $1 * /$

$/ * \beta$ value varies between 0 to $1 * /$

$1 * \mathrm{n}$ is number of fireflies*/

2. Initialize random population:

$x=\operatorname{rand}()$;

3. Initial population evaluation using the objective function:

Objective $=\min \left(a Z_{1}+b Z_{2}+c Z_{3}\right)$

4. Define intensity at cost $(x)$ of each individual

5. While iteration < iteration:

6. For each $i=1$ to $n$

7. For each $j=1$ to $n$

8. If (intensity ${ }_{\mathrm{j}}>$ intensity $_{\mathrm{i}}$ )

9. Move firefliy $i$ to $j$ in particular dimension

10. End if

11. Evaluate new solution and updating the light intensity

12. End for $j$

13. End for $i$

14. Rank the fireflies and find the current best value

15. End while

16. Print the results

17. End firefly algorithm process

TABLE XIII

\begin{tabular}{cl}
\multicolumn{2}{c}{ CONTROL PARAMETERS } \\
\hline Index & \multicolumn{1}{c}{ Value } \\
\hline K $\Delta \omega$ & $5 \mathrm{pu}$ \\
K $\Delta \mathrm{pe}$ & $1.462 \mathrm{pu}$ \\
$\mathbf{T 1}$ & $0.05 \mathrm{~s}$ \\
$\mathbf{T 2}$ & $0.02 \mathrm{~s}$ \\
$\mathbf{T 3}$ & $0.03 \mathrm{~s}$ \\
$\mathbf{T 4}$ & $0.01 \mathrm{~s}$ \\
$\mathbf{T w 2}$ & $10 \mathrm{~s}$ \\
$\mathbf{T w 3}$ & $10 \mathrm{~s}$ \\
\hline
\end{tabular}

\section{ACKNOWLEDGMENT}

The first author would like to thank Universitas Airlangga for funding this research through "Riset Kolaborasi Luar Negeri" grant. 


\section{REFERENCES}

1. Y. Pan et al., "Towards the robust small-signal stability region of power systems under perturbations such as uncertain and volatile wind generation," IEEE Trans. Power Systems, vol. 33, no. 2, pp. 1790-1799, 2017.

2. N. Yorino, M. Abdillah, Y. Sasaki, and Y. Zoka, "Robust power system security assessment under uncertainties using bi-level optimization," IEEE Trans. Power Systems, vol. 33, no. 1, pp. 352-362, 2017.

3. M. El-Shimy, A. Sharaf, H. Khairy, and G. Hashem, "Reduced-order modelling of solar-PV generators for small-signal stability assessment of power systems and estimation of maximum penetration levels," IET Generation, Transmission \& Distribution, vol. 12, no. 8, pp. 1838-1847, 2017.

4. D. Gautam, V. Vittal, and T. Harbour, "Impact of increased penetration of DFIG-based wind turbine generators on transient and small signal stability of power systems," IEEE Trans. Power Systems, vol. 24, no. 3, pp. 1426-1434, 2009.

5. X. Y. Bian, Y. Geng, K. L. Lo, Y. Fu, and Q. B. Zhou, "Coordination of PSSs and SVC damping controller to improve probabilistic small-signal stability of power system with wind farm integration," IEEE Trans. Power Systems, vol. 31, no. 3, pp. 2371-2382, 2016.

6. Y. Zhou, Y. Li, W. Liu, D. Yu, Z. Li, and J. Liu, "The stochastic response surface method for small-signal stability study of power system with probabilistic uncertainties in correlated photovoltaic and loads," IEEE Trans. Power Systems, vol. 32, no. 6, pp. 4551-4559, 2017.

7. H. Setiadi, N. Mithulananthan, and R. Shah, "Simultaneous parameter optimization for coordinated control of BESS and DIPSS using clonal selection," in IEEE PES Asia-Pacific Power and Energy Engineering Conference (APPEEC), 2018.

8. H. Setiadi, A. U. Krismanto, N. Mithulananthan, and M. Hossain, "Modal interaction of power systems with high penetration of renewable energy and BES systems," International Journal of Electrical Power \& Energy Systems, vol. 97, pp. 385-395, 2018.

9. H. Setiadi, N. Mithulananthan, and R. Shah, "Design of wide-area POD with resiliency using modified DEA for power systems with high penetration of renewable energy," IET Renewable Power Generation, vol. 13, no. 2, pp. 342-351, 2019.

10. H. Setiadi, N. Mithulananthan, R. Shah, K. Y. Lee, and A. U. Krismanto, "Resilient wide-area multi-mode controller design based on Bat algorithm for power systems with renewable power generation and battery energy storage systems," IET Generation, Transmission \& Distribution, vol. 13, no. 10, pp. 1884-1894, 2019

11. M. Yin, G. Li, M. Zhou, and C. Zhao, "Modeling of the wind turbine with a permanent magnet synchronous generator for integration," in IEEE Power Engineering Society General Meeting, 2010.

12. WECC, "WECC guide for representation of photovoltaic systems in large-scale load flow simulations," WECC Renewable Energy Modeling Task Force, Tech. Rep, 2010.

13. "Standard Report for Variable Generation," NERC Special Report, Atlanta, GA, 2010.

14. K. Clark, N. W. Miller, and R. Walling, "Modelling of GE solar photovoltaic plants for grid studies," General Electrical International, Inc., Schenectady, NY, 2010.

15. M. El-Shibini, H. Rakha, "Maximum power point tracking technique," in IEEE Integrating Research, Industry and Education in Energy and Communication Engineering, Mediterranean, 1989.

16. R. Shah, N. Mithulananthan, and K. Y. Lee, "Large-scale PV plant with a robust controller considering power oscillation damping," IEEE Trans. Energy Conversion, vol. 28, no. 1, pp. 106-116, 2013.

17. J. Paserba, "Analysis and control of power system oscillation," CIGRE special publication, vol. 38, no. $07,1996$.

18. WECC-0107 Power System Stabilizer (PSS) Design and Performance WECC Regional Reliability Standard, VAR-501-WECC-3-Power System Stabilizer, 2016.

19. S. Chandra, D. F. Gayme, and A. Chakrabortty, "Coordinating wind farms and battery management systems for inter-area oscillation damping: A frequency-domain approach," IEEE Trans. Power Systems, vol. 29, no. 3, pp. 1454-1462, 2014.

20. T. E. Marlin, Process Control: Designing Process and Control Systems for Dynamic Performance. McGraw-Hill, 1995.

21. Sajadi, R. Preece, and J. Milanovic, "Establishment multidimensional transient stability boundaries for power systems with uncertainties," in IEEE Power Systems Computation Conference (PSCC), 2018.

22. M. Shakarami,I. F. Davoudkhani, "Wide-area power system stabilizer design based on grey wolf optimization algorithm considering the time delay," Electric Power Systems Research, vol. 133, pp. 149-159, 2016.

23. X.-S. Yang, "Firefly algorithms for multimodal optimization," in International symposium on stochastic algorithms, Springer, pp. 169-178, 2009.

24. X.-S. Yang, Nature-inspired Metaheuristic Algorithms. Luniver press, 2010.

25. X.-S. Yang, "Metaheuristic Optimization," Scholarpedia, vol. 6, no. 8, 2011.

26. X.-S. Yang, Cuckoo Search and Firefly Algorithm: Theory and Applications. Springer, 2013.

27. "IEEE Recommended Practice for Excitation System Models for Power System Stability Studies," IEEE Std 421.5-2016 (Revision of IEEE Std 421.52005), pp. 1-207, 2016, doi: 10.1109/IEEESTD.2016.7553421.

28. "Peraturan Pemerintah Republik Indonesi No. 79 Tahun 2014 Tentang Kebijakan Energu Nasional," Jakarta, 2014.

29. R. Shah, N. Mithulananthan, and K. Y. Lee, "Large-scale PV Plant with a Robust Controller Considering Power Oscillation Damping," IEEE Trans. Energy Conversion, vol. 28, no. 1, pp. 106-116, 2013.

30. Y. Zhang and R. Preece, "A comprehensive methodology for assessing power oscillation damping controllers for HVDC-based system stabilization," in 2015 IEEE Eindhoven PowerTech, 2015, pp. 1-6. 